\title{
Load-Carrying Performance and Hydrostatic Tests of Encapsulated Anchor Systems for Unbonded Post-Tensioning Single-Strands
}

\author{
Ah Sir Cho, and Thomas H.-K. Kang*
}

(Received September 30, 2017, Accepted January 6, 2018)

\begin{abstract}
ACI 318-14 and 423.7-14 require the use of encapsulation system for an unbonded single-strand tendon for the purpose of corrosion protection and enhanced durability. In this study, load-carrying performance and hydrostatic tests were conducted for a newly developed, unbonded post-tensioning (PT) anchor with encapsulation, following the guidelines put forth in KCI-PS101 and ACI 423.7-14. The static load and fatigue tests as part of this study were used to evaluate the anchorage system behavior under static and cyclic loads, respectively. The hydrostatic test was used to demonstrate that the encapsulation system withstood at least $9.3 \mathrm{kPa}$ of water pressure in a $24 \mathrm{~h}$ period according to ACI 423.7-14, and thus has been proven to promote the durability of unbonded PT single-strand tendons. Additionally, the push-in and jacking tests were used to assess the compressive and tensile strengths of the anchor as used in the field. Although these tests were not performed to failure for safety reasons, the anchor endured at least 1.18 and 1.02 times the nominal ultimate strength of a strand in each test, respectively. The authors' previous load transfer tests were also reported in this paper, showing that test specimens with only two horizontal backup bars were capable of resisting at least 1.7 times the nominal ultimate strength of a strand. Based on the favorable results from the loadcarrying performance and hydrostatic tests, the developed encapsulated anchor systems are being applied in actual practice as an economically feasible option in Korean PT industry and are expected to improve the corrosion resistance and durability of posttensioned structures.
\end{abstract}

Keywords: post-tensioned anchor, encapsulation, corrosion, durability, unbonded, performance test, static load test, fatigue test, hydrostatic test.

\section{Introduction}

The post-tensioning (PT) method provides a pre-compressive force in concrete by jacking high-strength steel strands after the concrete hardens (Kang et al. 2009b; Yang and Kang 2011; Lee et al. 2016). This method is mainly used for floor slabs/beams in buildings, bridge girders and containment structures, because it enables reduction in the member volume, providing greater control over deflections and providing essential confinement. Given both the structural and regulatory limitations on slab thickness, a singlestrand PT tendon system is commonly used for office and residential buildings. An unbonded single-strand tendon consists of a seven wire strand that is coated with grease and high-density polyethylene (HDPE), post-tensioned anchors at both ends, and encapsulated systems and other accessories. Note that the sheathing of extruded single-strand tendons should be made of high-density polyethylene

Department of Architecture \& Architectural Engineering, Seoul National University, Seoul, South Korea.

*Corresponding Author; E-mail: tkang@snu.ac.kr Copyright (c) The Author(s) 2018. This article is an open access publication
(HDPE) or polypropylene (HDPP); however, the material for plastic coating to protect the anchors from corrosion is not specified in ACI 423.7-14. For the post-tensioned anchors used in this study, linear low-density polyethylene (LLDPE) coating with $2 \mathrm{~mm}$ thickness on average is applied. The benefits of using such unbonded PT systems include easier installation of strands and no need for grouting.

Since the adoption of ACI 423.7-14 (Joint ACI-ASCE Committee 423 2014) in ACI 318-14 (ACI Committee 318 2014), the encapsulation of a single-strand PT tendon is required for elevated floors in the United States. Given the condition that PT strands are not bonded to or covered by concrete, the use of encapsulated anchor systems is much needed for the durability of the strand. In this paper, both load-carrying performance and hydrostatic tests of unbonded PT anchors are conducted in accordance with existing specifications or industry/manufacturer standards. The tested encapsulated single-strand anchor was developed by the authors for the first time in Korea, which would provide cost effectiveness and practical feasibility compared to imported anchors. Load-carrying capacity, sustainability, and durability of concrete structures with a variety of materials/ products are important considerations and should be meticulously considered (Kang et al. 2009a, 2011, 2014; Yang et al. 2014). The durability design requirements for reinforced and post-tensioned concrete structures are becoming 
more stringent in the 21 st century than a few past decades. The current experimental study is expected to contribute to PT concrete industry in this aspect.

\section{Encapsulated Anchor System}

The authors conducted static load and load transfer tests for their developed post-tensioned single-strand anchor (Cho et al. 2015). The authors also performed the load transfer tests for three different anchorages with respect to anchor geometry and reinforcement detailing in the anchorage zone (Cho and Kang 2017). WJE (2006) conducted fatigue testing of post-tensioned anchors and couplers for $12.7 \mathrm{~mm}$ diameter single-strand tendons, and Walsh and Kurama (2009) performed static load and fatigue tests of bare anchors and barrel anchors for both 12.7 and $15.2 \mathrm{~mm}$ diameter strands. Both institutions followed the testing procedure and acceptance criteria of AC303 (ICC-ES 2011), and their test results met the criteria. However, these research programs tested a bare (or barrel) anchor for all performance tests and did not include hydrostatic tests, as it was not a corrosion-protective encapsulated system. Previously, Hayes Industries Ltd. (2014) performed hydrostatic tests of encapsulated anchor systems under $11.0 \mathrm{kPa}$ for $24 \mathrm{~h}$ using a PVC hydrostatic test chamber in accordance with Section 2.2.6 of PTI M10.2-00 (PTI 2000), which is similar to Sections 9.3(a) and 9.6 of ACI 423.7-14. PSI (2015) did a similar hydrostatic test but under more severe condition, that is, under $68.8 \mathrm{kPa}$ for $24 \mathrm{~h}$ seemingly in accordance with Sections 9.3(b) and 9.6 of ACI 423.7-14 (though the report indicated that it was tested according to Section 2.6.8 of ACI 423.7-07 (Joint ACI-ASCE Committee 423 2007), which has only one hydrostatic pressure of $8.6 \mathrm{kPa}$ ). Both hydrostatic tests revealed that the encapsulation systems satisfied the criteria with no water leak.

To prevent contact with water/moisture, a bare anchor is coated and covered by coating of LLDPE plastic materials (i.e., encapsulated). Figure 1 shows an encapsulated anchor that has been developed by the authors in Korea, and is being manufactured and supplied for use in several building projects. The sleeve is plastic-molded together with the plastic cover of an anchor as an integrated encapsulation.

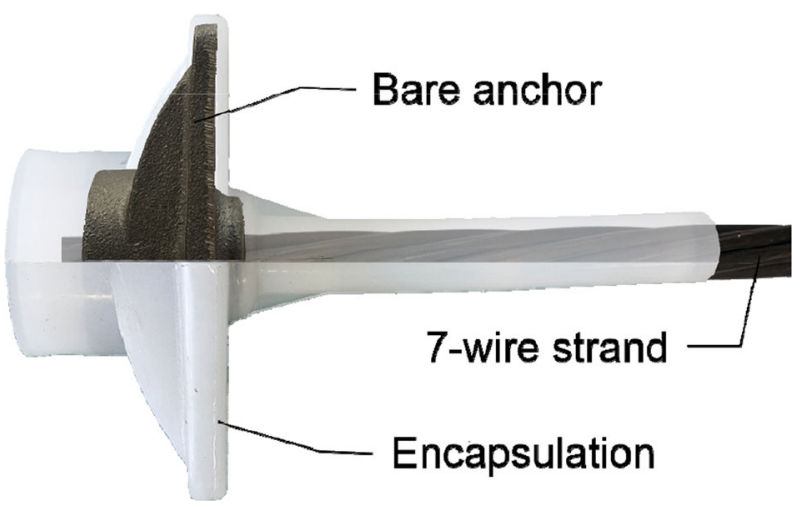

Fig. 1 Prototype of developed encapsulated anchor.
The tightness of an end cap should also be checked against moisture intrusion. In this study, both performance and hydrostatic tests are carried out for the developed encapsulated anchor systems with $15.2 \mathrm{~mm}$ diameter 7-wire strands to evaluate their corrosion resistance and load-carrying capacity.

\section{Test Methods}

\subsection{Static Load Test}

A series of static load tests were carried out to assess the strength of an anchor and evaluate its behavior, as well as that of the wedge, strand, and strand-wedge connection. The test was conducted according to the Korean specification, KCI-PS 101, which is a part of the Appendix of KCI (2010). This is similar to ETAG 013 (EOTA 2002). After pre-jacking at about 10 to $15 \%$ of the minimum ultimate tensile strength (MUTS), displacement gauges were installed. Then, tensile loading was increased up to $80 \%$ of the MUTS of the strand.

Three specimens (SLT1 3) were tested. To control both load and displacement, the live-end anchor was set onto a steel frame, which was moved by an actuator, rather than a jacking device (Fig. 2a). LVDT $01 \sim 04$ (Fig. 2b) measured the displacement of an anchor plate, core (king) wire, one of the six helical (perimeter) wires, and one set of the wedges. The free length of the strand was $3500 \mathrm{~mm}$. For SLT3, LVDT 05 and LVDT 06 (Fig. 2c) were added to measure the elongation in the middle of the strand, thereby satisfying stipulations in ACI 423.7 (Joint ACI-ASCE Committee 423 2014).

After pre-jacking, displacement measurements confirmed that the load increased at a rate of $100 \mathrm{MPa} / \mathrm{min}$. up to $80 \%$ of MUTS. During the first half hour of testing under the $80 \%$ of MUTS, the wedge and strand were settled into the anchor and stabilized. For safety, the loading was stopped just before the fracture of the strand. Only the test for SLT3 was carried out until the strand fractured.

\subsection{Fatigue Test}

A fatigue test was performed to evaluate the anchorage performance during fatigue or under cyclic loading (Fig. 3). Unlike in bridges, the fatigue in buildings has a negligible effect on a tendon (PTI 2006); nonetheless, fatigue testing is required by KCI-PS101 (KCI 2010) for unbonded tendons. The testing methodology in this study followed in accordance with KCI-PS101. Because it was not easy to develop a jig to hold the plastic-coated anchor, it was tested using bare anchors.

The strand was inserted into the anchor with a wedge, and each anchor was fixed to the steel plates. Both ends were fixed with hinges so that the longitudinal axis was maintained parallel to the ground plane when the strand was elongated. The initial free length of the specimen was $1000 \mathrm{~mm}$. One end was fixed, with repeated loading applied using an actuator at the other end. The repeated loads 


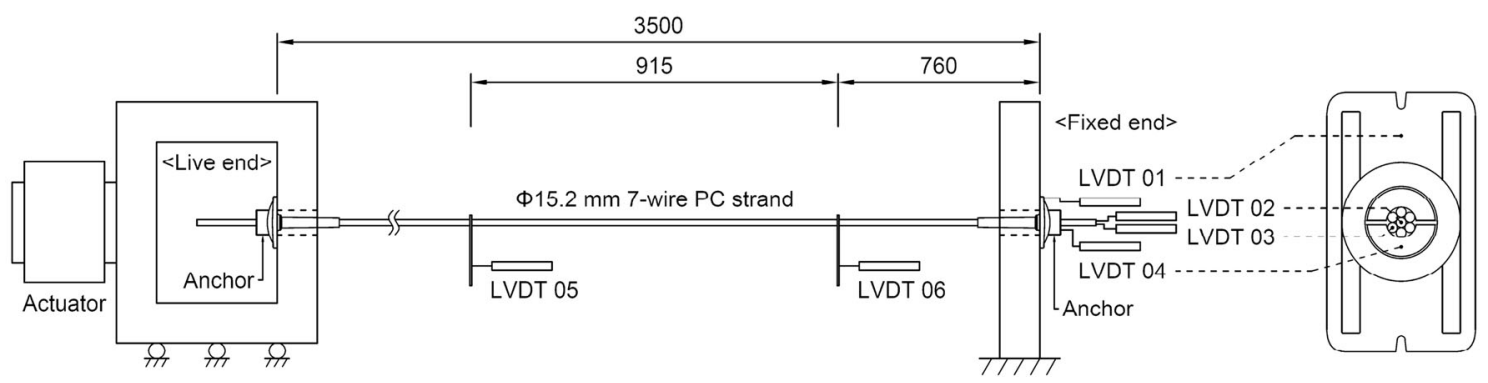

(a)

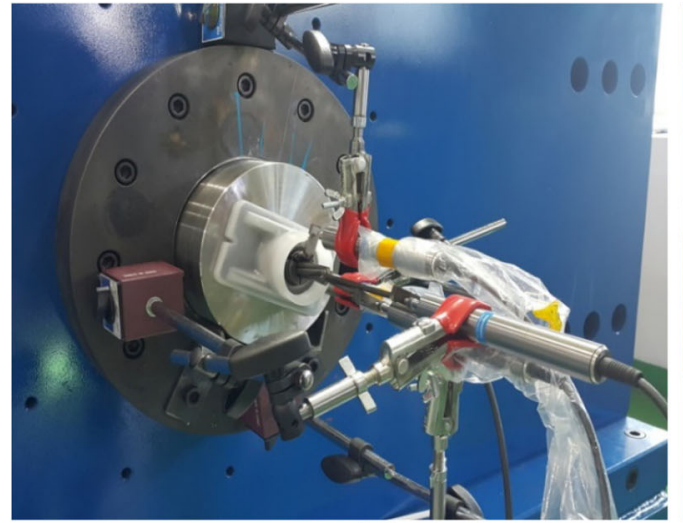

(b)

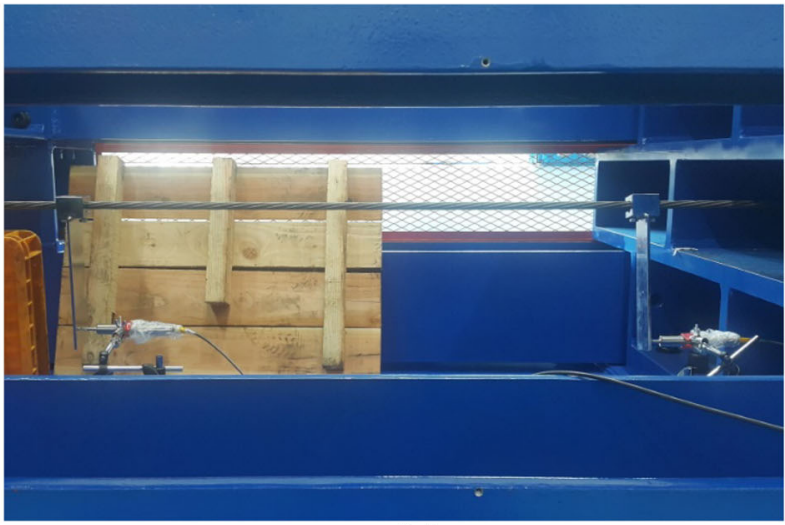

(c)

Fig. 2 Setup of static load test. a Section view (unit: $\mathrm{mm}$ ), b fixed end, and c middle of free length.

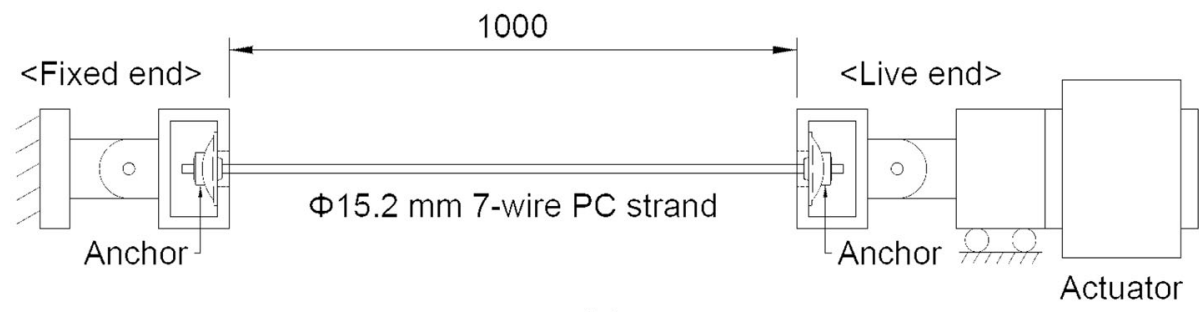

(a)

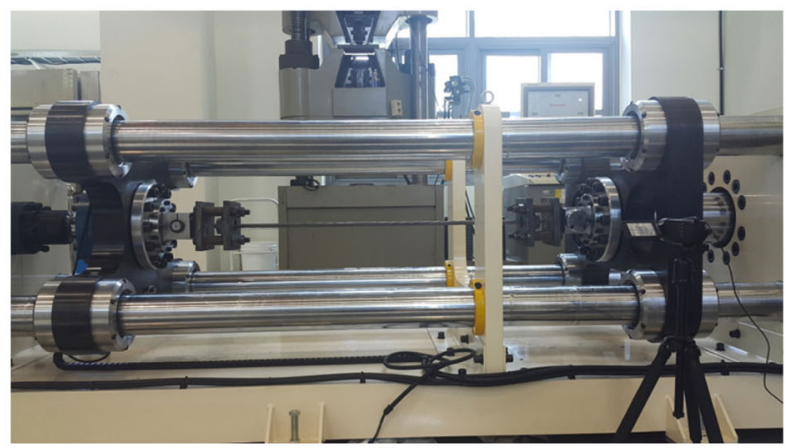

(b)

Fig. 3 Setup of fatigue test. a Section view (unit: $\mathrm{mm}$ ) and $\mathbf{b}$ test setup.

between 160 and $171 \mathrm{kN}$ were applied at $3 \mathrm{~Hz}$ for 2,000,000 cycles.

\subsection{Hydrostatic Test}

Hydrostatic tests were performed to affirm watertight efficacy for encapsulation systems. This testing methodology was applied, exactly meeting the specifications of Section 9.3 of ACI 423.7-14. Instead of a wedge, a white tissue was placed inside the anchor cavity, which was covered by an end cap. The end of the sleeve was sealed with tape as used in the field. A dye was added to the water to examine whether the water entered into the anchor cavity after the experiment. For $24 \mathrm{~h}$, four encapsulated anchor specimens (Fig. 4a) were placed in a hydrostatic pressure chamber (Fig. 4b), with a hydrostatic pressure of over $8.6 \mathrm{kPa}$. 


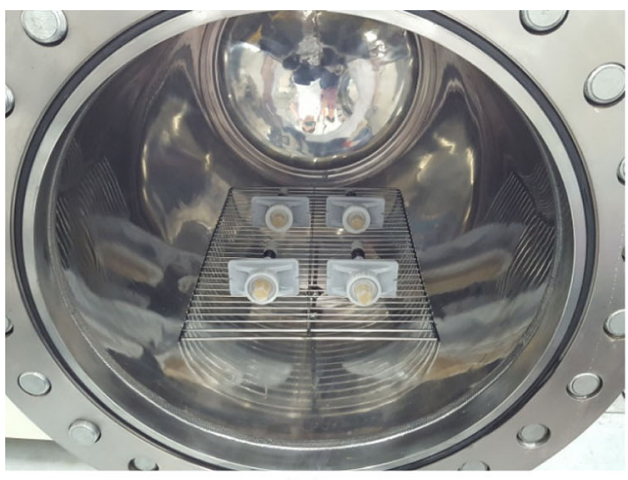

(a)

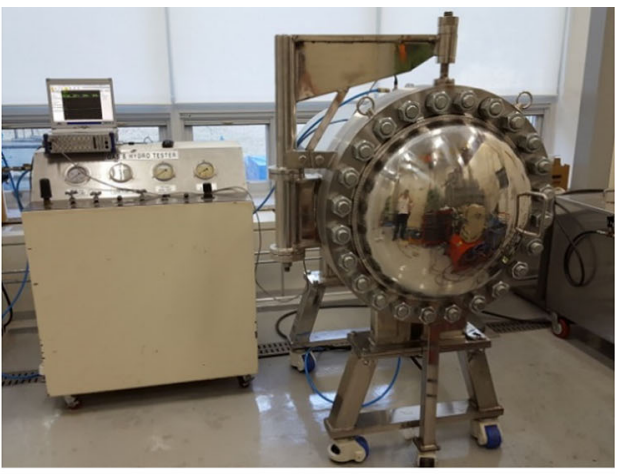

(b)

Fig. 4 a Four specimens inside hydrostatic test chamber and b overview of hydrostatic test chamber.

\subsection{Push-in Test}

Similar to the wedge plate test specified by Sections 4.1.1 and 4.1.2 of PTI M50.1-98 (PTI 1998), push-in tests were performed to evaluate the strength of an anchor when a twopiece wedge was pushed in, with and without an offset or gap $(\Delta g)$ between the two wedge pieces, as shown in Fig. 5. To simulate the actual prestressing force of a tendon, a strand was inserted into an anchor and gripped by a two-piece wedge Then the load was applied to the strand, not on the wedge. This test can be easily carried out without jacking or pulling, and is suitable for measuring the maximum capacity of an anchor system itself with actual wedge pieces seated in.

A total of six specimens were tested, including one specimen of a non-encapsulated bare anchor. A wooden board was used to support the bare anchor against a steel block, due to its uneven front surface of the bearing plate. Three of the encapsulated anchors were tested with a gap $\Delta g$ between the two pieces of the wedge, akin to a poor condition that may occur in the actual construction field (Fig. 5a). The test setup is shown in Fig. 5b. The load was applied until the anchor fractured, which was not easy to perform during the load transfer test as the concrete test block failed first.

\subsection{Jacking Test}

A jacking test is a simple experiment which physically simulates the post-tensioning process. As shown in Fig. 6, an anchor was fixed to a steel block, and the strand was jacked from the other side. The jacking force was measured by a load cell installed between the live-end anchor and the jack. This setup is similar to that used in precast plants.

\section{Test Results and Discussion}

\subsection{Static Load Test}

For all specimens, the load of $80 \%$ of the MUTS was maintained for $1 \mathrm{~h}$, after which the load was increased up to over $260 \mathrm{kN}$ (Fig. 7). Only the SLT3 specimen was tested up to strand fracture; however, the LVDTs were removed after 1 hour to adhere to equipment safety guidelines. The measured maximum loads $(268.5,266.6$ and $270.5 \mathrm{kN})$ exceeded $100 \%(260 \mathrm{kN})$ of the MUTS for all specimens, indicating that the load-carrying capacity has been confirmed.

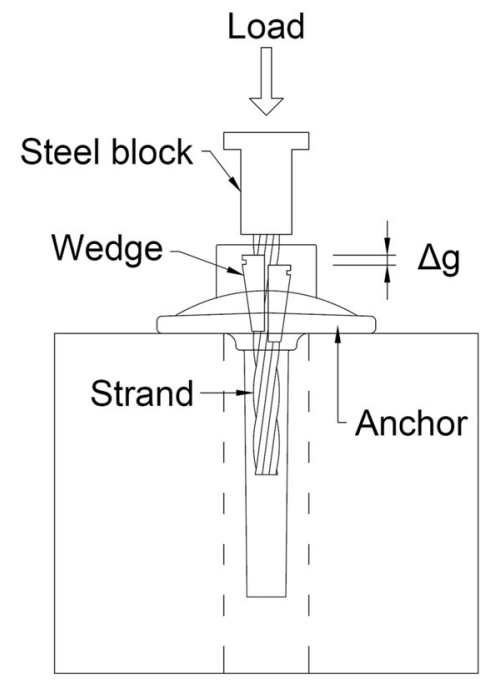

(a)

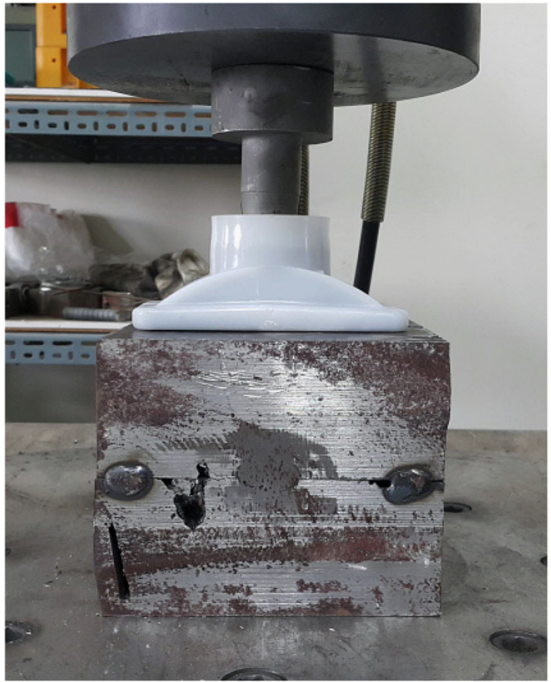

(b)

Fig. 5 Setup for push-in test. a Section view and $\mathbf{b}$ test setup. 


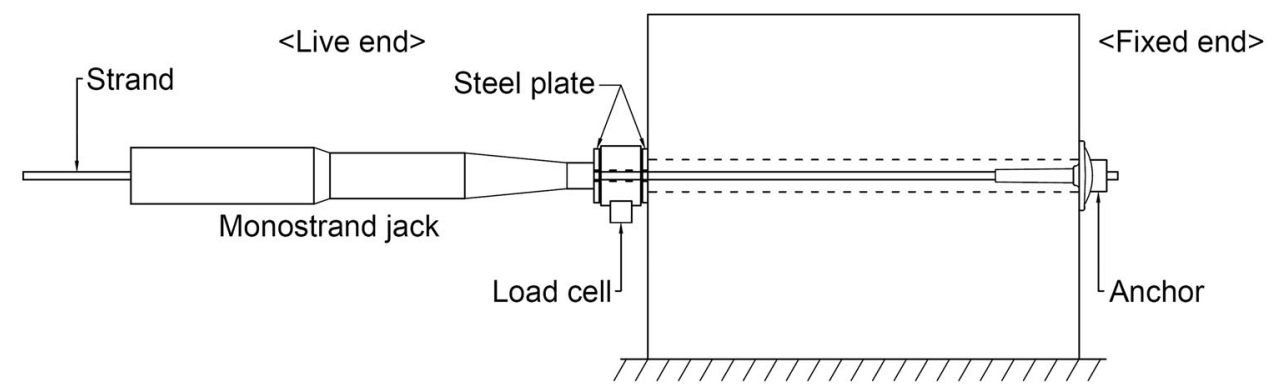

(a)

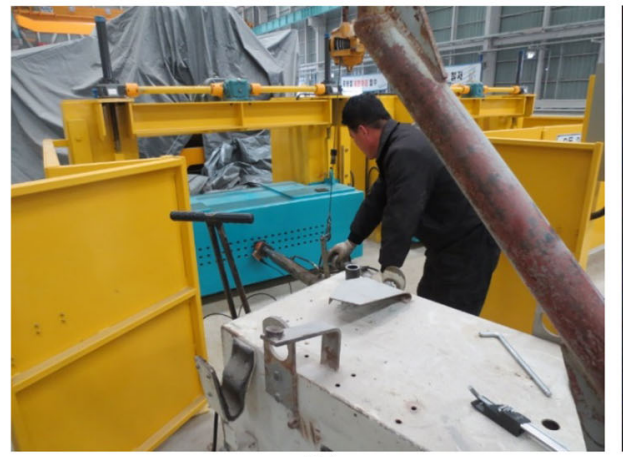

(b)

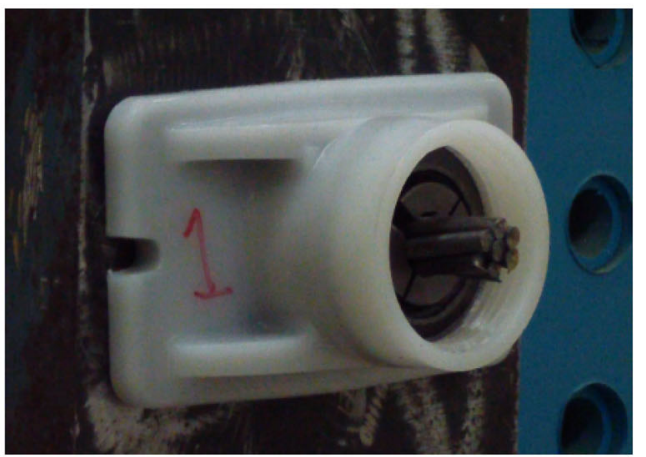

(c)

Fig. 6 Setup of jacking test. a Section view, $\mathbf{b}$ jacking process at live end, and $\mathbf{c}$ fixed end.
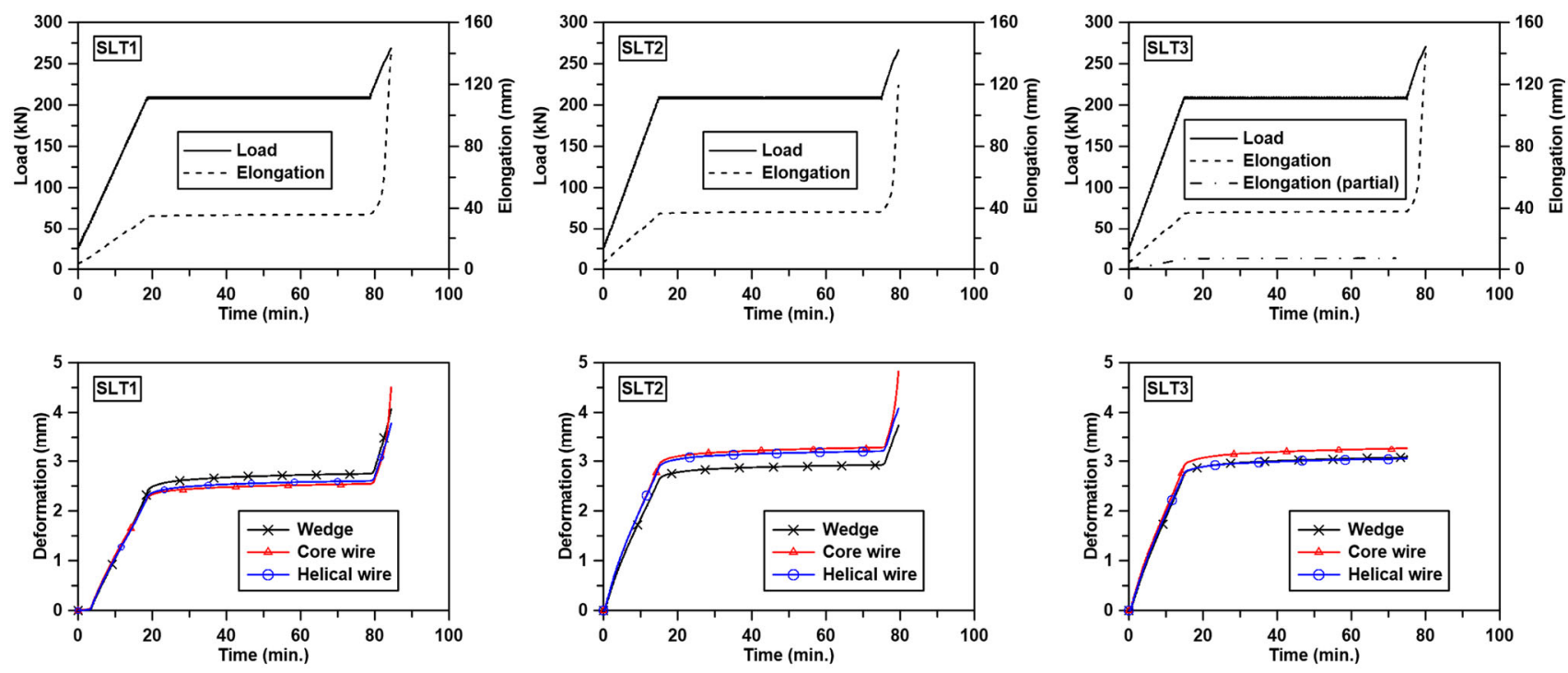

Fig. 7 Results of static load tests.

The anchor slip displacements (suction) of the wedge, core wire, and helical wire were calibrated by subtracting the displacement of the anchor plate from the total measured value. At $80 \%$ of the MUTS, the anchorage slip displacement was only approximately $3 \mathrm{~mm}$, which was maintained with little variation. According to the EOTA document (EOTA 2013), the slip displacement at a fixed end (i.e., wedge draw-in) should be in the range of $3-5 \mathrm{~mm}$. This result demonstrated the stable performance of the tendon assembly.

The partial elongation in the middle of the SLT3 specimen was obtained using the difference between the displacements of LVDT 05 and LVDT 06. The measured portion was much close to the fixed end location. The partial elongation in the middle was very small because the measured original length was only a portion $(26 \%)$ of the total free length.

The relationship between the elongation percentage (strain) and stress is plotted in Fig. 8. The elongation percentage was increased rapidly to over $3 \%$ beyond $1800 \mathrm{MPa}$. In the STL3 specimen, fracture occurred at about $4 \%$ elongation. The elongation percentage results demonstrate the sufficient ductility of the tested strands prior to facture and satisfatory performance of the tested tendon assemblies. The partial elongation for the STL3 specimen was approximately $75 \%$ of the total elongation, as the stressstrain curve in Fig. 8 was located lower than the rest of the 


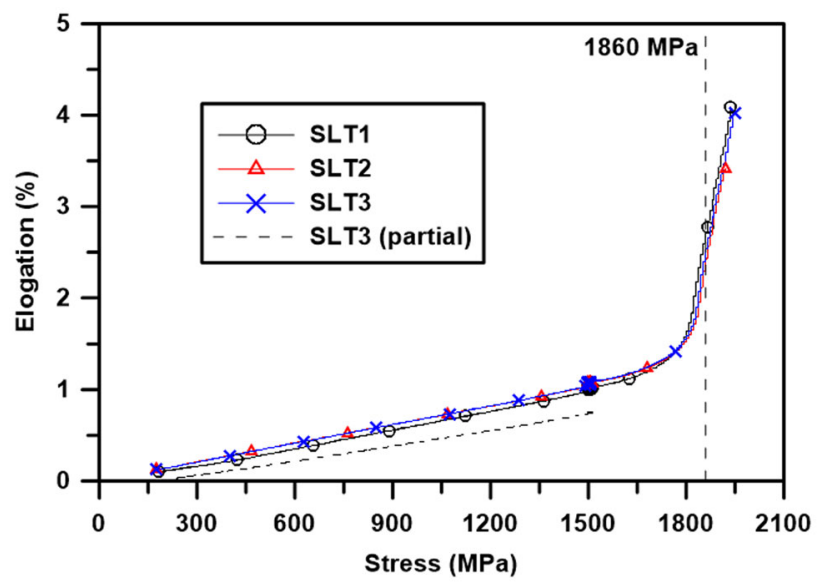

Fig. 8 Relationship between elongation percentage and stress.

curves. This is a new finding that the tensile strain increased more at the jacking end than at the fixed end. See Fig. 2(a) where the measured portion between the LVDT 05 and LVDT 06 was located much closer to the fixed end, and note that the LVDT 05 and LVDT 06 were removed after one hour holding period.

\subsection{Fatigue Test}

The fatigue load test, also called the high cycle dynamic tensile test, was performed over more than 7 days to generate 2,000,000 loading cycles. The KCI-PS101 specifications, which are the same as those of ETAG 013, were used as a testing protocol. The applied cyclic loads are shown in Fig. 9. Since the actuator was operated by a hydraulic pump, there were slight variations in load amplitude. Despite that, the overall loading range was steadily maintained as specified by KCI-PS101 or ETAG 013 throughout 7 days and beyond. The data from the day four to seven were not obtained due to the equipment's recording storage problem. No cracking of steel was observed in the anchors and wedges after the completion of the test (Fig. 10). No fracture of steel also has occurred, demonstrating the satisfactory fatigue behavior of the tested tendon assemblies. This was based on the third party's visual observation in accordance with KCI-PS101 or ETAG 013. It is noted that the fatigue

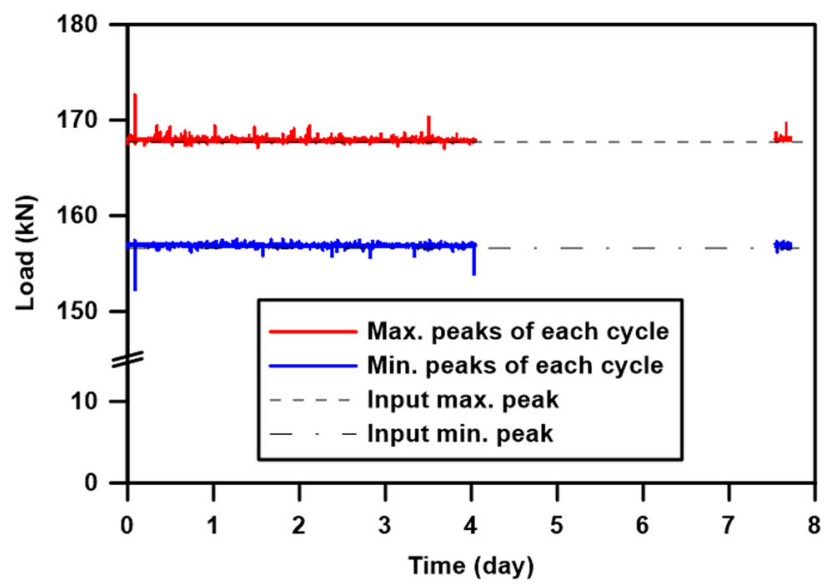

Fig. 9 Results of fatigue test. test was conducted in an independent commercial testing laboratory. The long-term service life is related to the fatigue behavior. Therefore, the data herein will help increase practical applications of the developed encapsulated anchor system.

\subsection{Hydrostatic Test}

The hydraulic pressure in the equipment was maintained between 9.3 and $9.8 \mathrm{kPa}$ for $24 \mathrm{~h}$, as shown in Fig. 11a, which exceeded the minimum ACI 423 -specified pressure of $8.6 \mathrm{kPa}$. Even though the pressure was attempted to remain constant, there was a modest variation during $24 \mathrm{~h}$. After the hydrostatic test for $24 \mathrm{~h}$, all the moisture on the outside surface of the anchor was removed, and the fastened end cap was opened (unfastened by hand). No paint or water was observed as the white tissues placed inside the cavity were not affected by the paint or internal moisture at all (Fig. 11b). Next, plastic accessories were disassembled, and it was re-confirmed that there was no water intrusion in the anchorage system. Because the use of encapsulated PT systems is now required in the U.S. for all elevated unbonded PT floors and would possibly be required even for slabson-ground in the U.S. or for PT construction in Korea soon, the test results in this study will help provide viable options for those in need and promote application of more durable PT systems. Because of the superior watertightness of encapsulation systems and low probability of damaging the coating during transportation, plastic encapsulation is only permitted by ACI 423.7-14 (epoxy coating is no longer permitted).

\subsection{Push-in Test}

The results of the push-in tests are shown in Fig. 12 and Table 1. Some of the specimens were not pushed towards failure due to safety concerns. Even so, the measured maximum values exceeded the nominal ultimate strength of a strand $(260 \mathrm{kN})$ by far. It was possible because this test had nothing to do with strand performance, as the pushing force was applied up to or almost up to failure of the cast-iron anchor itself. The large slip in the bare anchor was due to the squeeze put on the wooden board. The encapsulated anchors (P1 5) also exhibited small compressive slips due to the squeezed plastic cover.

Specimens P3, P4, and P5 had staggered wedges, and two pieces of the wedges had an average step height $\Delta g$ of $7.32 \mathrm{~mm}$. After the test, the intentionally given offset $\Delta g$ was decreased to an average of $6.28 \mathrm{~mm}$. This reduction of $1.04 \mathrm{~mm}$ on average was due to additional slip of one wedge piece while the wedges were set inside the cavity.

\subsection{Jacking Test}

The results of jacking tests are summarized in Table 2. Because of limitations in the jacking device, the strand was not pulled up to fracture and stopped after exceeding the MUTS. The average of all maximum loads was $264.8 \mathrm{kN}$, approximately $2.6 \%$ greater than the nominal tensile force $(260 \mathrm{kN})$ of a $15.2 \mathrm{~mm}$ diameter seven wire strand. On average, the pre-jacking load was $27.8 \mathrm{kN}$, about $10.5 \%$ of 


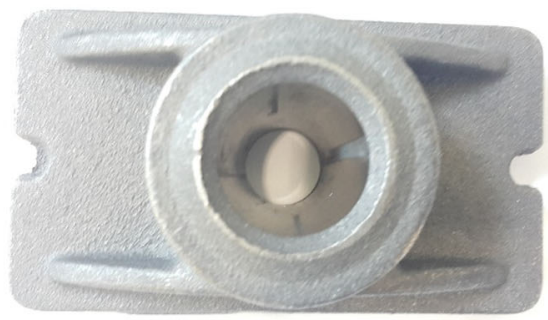

(a)
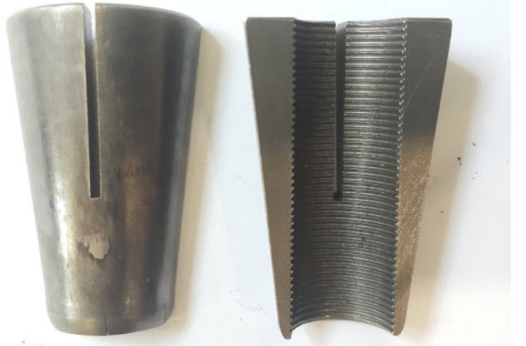

(b)

Fig. 10 Bare anchor and wedge after fatigue testing in accordance with KCl-P101 and ETAG 013. a Bare single-strand anchor and $\mathbf{b}$ two-piece wedge.

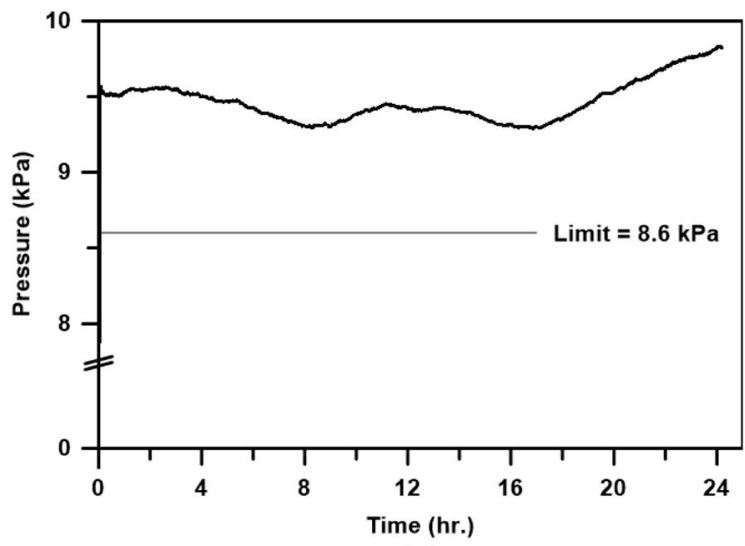

(a)

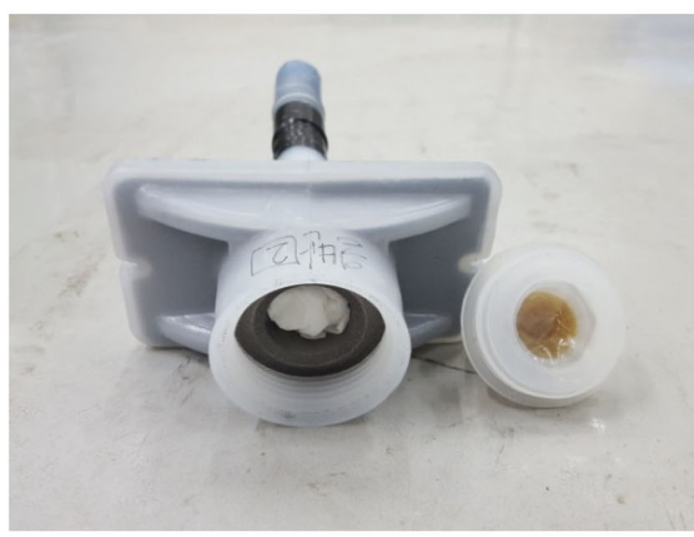

(b)

Fig. 11 Results of hydrostatic tests. a Pressure over time and $\mathbf{b}$ photo taken after hydrostatic test.

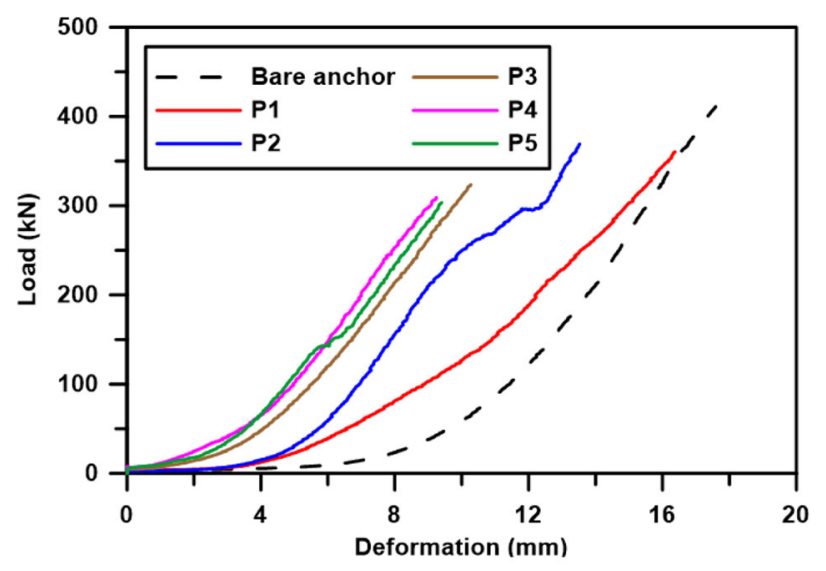

Fig. 12 Results of push-in tests. the maximum load strength or $10.8 \%$ of the nominal tensile force of the strand. This was done to remove any slack prior to full jacking. The jacking test results re-confirmed that the developed encapsulated anchor itself has sufficient loadcarrying capacity.

\section{Load Transfer Test}

Cho et al. (2015) previously conducted load transfer tests of the same bare anchors according to KCI-PS101. Horizontal backup bars (HB) and hairpin bars (HP) were used as independent variables. Table 3 summarizes the load transfer test results, with more details provided in the reference (Cho

Table 1 Maximum loads and changes in gap between two wedge pieces.

\begin{tabular}{c|c|c|c}
\hline \multirow{2}{*}{ Specimen } & Maximum load $(\mathrm{kN})$ & \multicolumn{2}{|c}{$\Delta g(\mathrm{~mm})$} \\
\cline { 3 - 4 } & & Before & After \\
\hline \hline P1 & 359.3 & - & - \\
\hline P2 & 370.3 & - & 6.56 \\
\hline P3 & 324.3 & 7.84 & 6.17 \\
\hline P4 & 311.8 & 7.41 & 6.10 \\
\hline
\end{tabular}


Table 2 Pre-jacking loads and maximum loads in jacking tests.

\begin{tabular}{c|c|c}
\hline Specimen & Pre-jacking load $(\mathrm{kN})$ & Maximum load (kN) \\
\hline \hline J1 & 27.3 & 265.0 \\
\hline J2 & 37.5 & 266.8 \\
\hline J3 & 19.6 & 263.6 \\
\hline J4 & 26.8 & 263.8 \\
\hline
\end{tabular}

Table 3 Results of maximum loads in load transfer tests normailized by nominal tensile strengths of strands.

\begin{tabular}{|c|c|c|c|c|c|c|}
\hline & & \multicolumn{4}{|c|}{ Hairpin bars (HP) } & \multirow[t]{2}{*}{ Remarks } \\
\hline & & None & D10 & D13 & D16 & \\
\hline \multirow{4}{*}{$\begin{array}{c}\text { Horizontal backup } \\
\text { bars }(\mathrm{HB})\end{array}$} & None & - & - & - & - & \\
\hline & \multirow[t]{2}{*}{ D13 } & $\begin{array}{l}1.89^{\mathrm{a}} \\
1.75^{\mathrm{b}}\end{array}$ & $\begin{array}{l}2.06^{\mathrm{a}} \\
1.96^{\mathrm{b}}\end{array}$ & $\begin{array}{l}1.82^{\mathrm{a}} \\
2.04^{\mathrm{b}}\end{array}$ & - & $\begin{array}{l}\text { HB located just in } \\
\text { front of bearing } \\
\text { plate }\end{array}$ \\
\hline & & $\begin{array}{l}1.85^{\mathrm{a}} \\
1.70^{\mathrm{b}}\end{array}$ & $\begin{array}{l}1.89^{\mathrm{a}} \\
1.88^{\mathrm{b}}\end{array}$ & - & - & $\begin{array}{c}\text { HB located inside } \\
\text { hairpin or at } \\
\text { equivalent } \\
\text { location }\end{array}$ \\
\hline & D16 & $\begin{array}{l}2.00^{\mathrm{a}} \\
2.17^{\mathrm{b}}\end{array}$ & - & $\begin{array}{l}2.03^{\mathrm{a}} \\
2.04^{\mathrm{b}}\end{array}$ & $\begin{array}{l}2.11^{\mathrm{a}} \\
2.05^{\mathrm{b}}\end{array}$ & \\
\hline
\end{tabular}

Measured concrete strength at testing day.

${ }^{\mathrm{a}} 20.0 \mathrm{MPa} ;{ }^{\mathrm{b}} 21.5 \mathrm{MPa}$.

et al. 2015). The values indicate the maximum compressive force divided by the nominal tensile strength of strands. With basic reinforcement (provided for all specimens as specified by KCI-PS101), the specimen without HB or HP could register 1.64 times its MUTS. In the case of specimens with two horizontal backup reinforcement, the ratio ranges from 1.7 to 1.89 , with a concrete compressive strength of 20 to $21.5 \mathrm{MPa}$. The concrete test block specimen included the single-strand anchor, duct and anchorage zone reinforcement (or not), as well as basic reinforcement that simulates the continuity of actual members, such that the load transfer and interaction between the anchor and concrete/anchorage zone reinforcement is verified. The authors' previously reported results were consistent with the recommendations by PTI (2006), proving that the bearing plate size and shape were adequate even without anchorage zone reinforcement.

\section{Applications to Real Buildings}

The developed encapsulated post-tensioned anchor systems have been used for several real building projects including residential, office and church buildings in Korea, which have been recently completed or currently under construction. Figure 13 shows an actual building project,

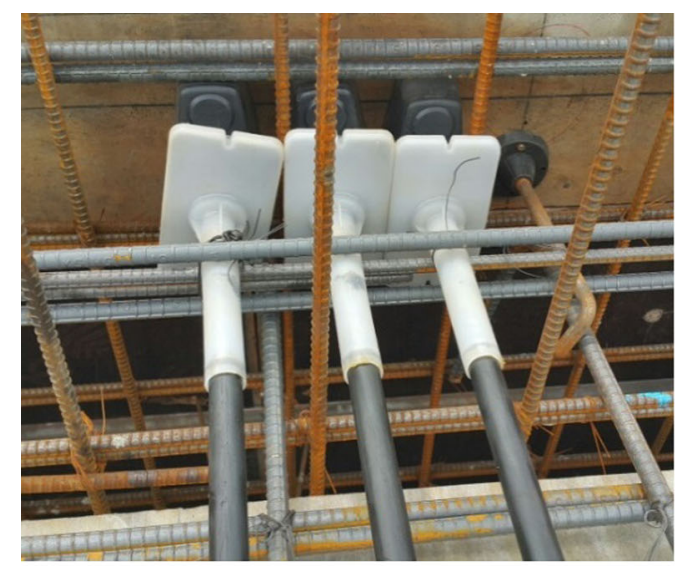

(a)

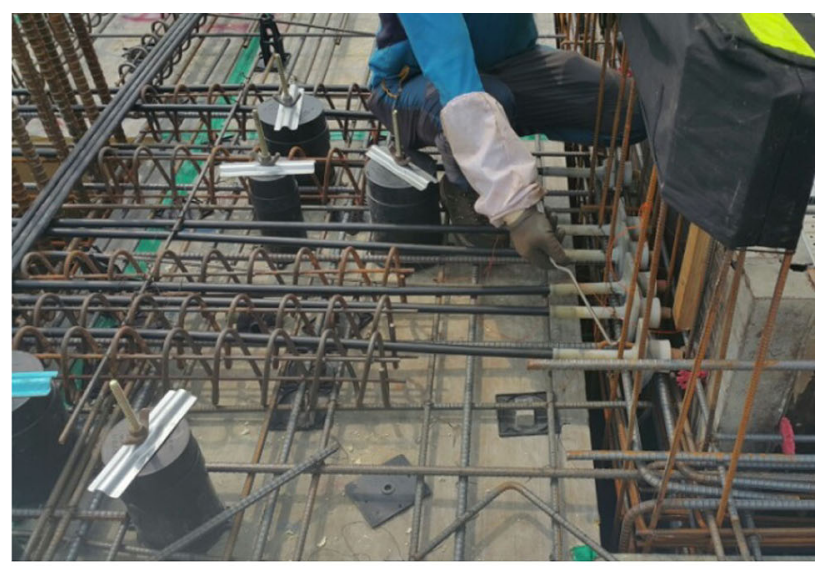

(b)

Fig. 13 Applications of developed encapsulated anchor systems. a Stressing end anchors and $\mathbf{b}$ fixed end anchors. 
where the developed systems were applied for the first time in Korea. To the authors' knowledge, the developed bare anchor was also the first Korean anchor for a single-strand tendon, as other anchors were either imported products or under other countries' license. Not to mention that it is the first Korean encapsulated system. The ACI 423.7-14 requirement for the use of encapsulated anchor systems is not yet required in Korea or by Korean Building Code (Architectural Institute of Korea 2016). However, because there is a growing demand to improve the durability and sustainability of PT structures with unbonded single-strand tendons, such corrosion-protective encapsulated anchor systems would be much needed in the near future in the region of East Asia.

\section{Conclusions}

In this study, load-carrying performance and hydrostatic tests of the developed encapsulation anchor were undertaken according to the Korean and U.S. testing standards. Static load and fatigue tests were used to evaluate the loadcarrying performance of the tendon assembly and mechanical interactions between the wedge and strand or anchor. The stable behavior was verified under static load and cyclic load. The anchor slip was only approximately $3 \mathrm{~mm}$, which was about half the typical wedge slip of 6 to $9 \mathrm{~mm}$. The fracture of the strand occurred at $4 \%$ elongation, which is considered to be quite large. The waterproofness of the encapsulation system was confirmed via a hydrostatic test.

In addition, a push-in test served as a compressive test of the anchor casting itself, while a jacking test functioned as a tensile test as used in the field. In the push-in test, the loading procedure was stopped for some specimens due to safety concerns, but all the anchors endured at least 1.18 times the nominal ultimate strength of the strand before the test was stopped or the anchor failed. The jacking test reflected the real-world condition, but there was no strand fracture under the maximum loading force of the jacking device, which was larger than the minimum ultimate tensile strength.

In the previous load transfer tests, the developed anchor could endure at least 1.7 times the nominal ultimate strength of the strand, with only two horizontal backup bars, at the specified concrete strength for jacking of about $21 \mathrm{MPa}$. Furthermore, the specimen without anchorage zone reinforcement resisted at least 1.64 times the nominal ultimate strength of the strand.

The test results in this study demonstrated both the loadcarrying and waterproofness performance of the developed encapsulated anchor system and would be expected to promote the durability of unbonded post-tensioning singlestrand tendons.

\section{Acknowledgements}

The work was funded by the National Research Foundation of Korea (2015-055508) and the Institute of Construction and Environmental Engineering of Seoul National University. Partial support from Samsung E\&T for push-in and jacking tests of KFA (Korea's First Anchor) is also acknowledged. Particularly, Y. W. Cho, B. K. Jeon, Y. N. Kim and J. K. Choi are sincerely appreciated for their assistance. The views expressed are those of authors, and do not necessarily represent those of the sponsors.

\section{Open Access}

This article is distributed under the terms of the Creative Commons Attribution 4.0 International License (http:// creativecommons.org/licenses/by/4.0/), which permits unre stricted use, distribution, and reproduction in any medium, provided you give appropriate credit to the original author(s) and the source, provide a link to the Creative Commons license, and indicate if changes were made.

\section{References}

ACI Committee 318. (2014). Building code requirements for structural concrete (ACI 318-14) and commentary. Farmington Hills, MI: American Concrete Institute.

Architectural Institute of Korea. (2016). KBC 2016: Korean building code. Seoul: Architectural Institute of Korea. (both in Korean and English).

Cho, A. S., Cho, Y. W., Jeon, B. K., \& Kang, T. H.-K. (2015). Development and performance test for unbonded posttensioned anchor. Journal of the Korea Concrete Institute, 27(1), 11-20. (in Korean).

Cho, A. S., \& Kang, T. H.-K. (2017). Load transfer test of spirally reinforced anchorage zone for banded tendon group. Journal of the Korean Association for Spatial Structures, 17(1), 59-67. (in Korean).

EOTA. (2002). Guideline for European technical approval: Posttensioning kits for prestressing of structures (ETAG 013). Brussels: European Organisation for Technical Approvals.

EOTA. (2013). European technical approval ETA-08/0012: Tensacciai post-tensioning system. Brussels: European Organisation for Technical Approvals.

Hayes Industries Ltd. (2014). Hydrostatic Test for Encapsulated Systems. Sugarland, TX: Hayes Industries Ltd.

ICC-ES. (2011). Acceptance criteria for post-tensioning anchorages and couplers of prestressed concrete (AC303). Birmingham: ICC Evaluation Service, LLC.

Joint ACI-ASCE Committee 423. (2007). ACI 423.7-07: specification for unbonded single-strand tendons and commentary. Farmington Hills: American Concrete Institute.

Joint ACI-ASCE Committee 423. (2014). ACI 423.7-14: specification for unbonded single-strand tendon materials. Farmington Hills, MI: American Concrete Institute. 
Kang, T. H.-K., Kim, W., Kwak, Y.-K., \& Hong, S.-G. (2011). Shear testing of steel fiber-reinforced lightweight concrete beams without web reinforcement. ACI Structural Journal, 108(5), 553-561.

Kang, T. H.-K., Kim, W., Kwak, Y.-K., \& Hong, S.-G. (2014). Flexural testing of reinforced concrete beams with recycled concrete aggregates. ACI Structural Journal, 111(3), $607-616$.

Kang, T. H.-K., Shin, M., Mitra, N., \& Bonacci, J. F. (2009a). Seismic design of reinforced concrete beam-column joints with headed bars. ACI Structural Journal, 106(6), $868-877$.

Kang, T. H.-K., Wallace, J. W., \& Elwood, K. J. (2009b). Nonlinear modeling of flat-plate systems. ASCE Journal of Structural Engineering, 135(2), 147-158.

KCI. (2010). Standard specification for concrete and commentary. Seoul: Korea Concrete Institute. (both in Korean and English).

Lee, J. D., Yoon, J. K., \& Kang, T. H.-K. (2016). Combined half precast concrete slab and post-tensioned slab topping system for basement parking structures. Journal of Structural Integrity and Maintenance, 1(1), 1-9.
PSI. (2015). Hydrostatic test report: project No. 0204833. La Porte: Professional Service Industries, Inc.

PTI. (1998). PTI M50.1-98: acceptance standards for posttensioning systems. Phoenix, AZ: Post-Tensioning Institute.

PTI. (2000). PTI M10.2-00: Specification for unbonded single strand tendons. Phoenix, AZ: Post-Tensioning Institute.

PTI. (2006). PTI TAB.1-06: Post-tensioning manual-sixth edition. Phoenix, AZ: Post-Tensioning Institute.

Walsh, K. Q., \& Kurama, Y. C. (2009) Behavior and design of unbonded post-tensioning strand/anchorage systems for seismic applications. Report\#NDSE-09-02, Department of Civil Engineering and Geological Sciences, University of Notre Dame, IN.

WJE. (2006) Sure-lock ${ }^{\circledR}$ and sure-lock ${ }^{\circledR}$ II post-tension anchorage and coupler testing. Report No. 2005.0971, Wiss, Janney, Elstner Associates, Inc., Northbrook, IL.

Yang, K.-H., \& Kang, T. H.-K. (2011). Equivalent strain distribution factor for unbonded tendon stress at ultimate. $A C I$ Structural Journal, 108(2), 217-226.

Yang, K.-H., Mun, J.-H., Cho, M.-S., \& Kang, T. H.-K. (2014). Stress-strain model for various unconfined concretes in compression. ACI Structural Journal, 111(4), 819-826. 